\title{
Efektivitas Islamic Parenting Training Untuk Meningkatkan Harga Diri Orangtua yang Memiliki Anak Retardasi Mental
}

\author{
Vivik Shofiah, Yulita Kurniawaty Asra, Hirmaningsih
}

\author{
Fakultas Psikologi UIN Sultan Syarif Kasim Riau
}

email: vivikdanu@gmail.com

\begin{abstract}
Abstrak
Penelitian ini bertujuan untuk mengetahui efektivitas Islamic parenting training dalam meningkatkan harga diri orangtua yang memiliki anak retardasi mental. Islamic parenting training merupakan suatu bentuk pelatihan tentang pengasuhan yang dilandaskan pada konsep Islam yang dapat dilakukan untuk membantu orangtua mengatasi masalah harga diri yang rendah.Hipotesis dalam penelitian ini adalah Islamic parenting training efektif untuk meningkatkan harga diri orangtua yang memiliki anak retardasi mental. Penelitian ini dengan menggunakan pendekatan eksperimen pre and post test one group design. Subjek penelitian lima orangtua yang memiliki anak retardasi mental di SLB Pelita Hati Pekanbaru. Alat ukur yang digunakan adalah skala harga diri dengan 45 aitem. Analisis dengan menghitung perbedaan mean harga diri pada masing- masing subjek sebelum dan sesudah mendapatkan Islamic parenting training, Berdasarkan hasil analisis data menunjukkan Islamic parenting training tidak memiliki pengaruh signifikan dalam peningkatan harga diri. Hal ini berarti Islamic Perenting training kurang efektif meningkatkan harga diri orang tua yang memiliki anak retardasi mental.
\end{abstract}

Kata Kunci : Islamic parenting, harga diri, retardasi mental

\section{Effectiveness Of Islamic Parenting Training In Improving Self-Esteem of Parents of Children With Mental Retardation}

\begin{abstract}
This study aims to determine the effectiveness of Islamic parenting training in improving self-esteem of parents of children with mental retardation. Islamic parenting training is a form of training on parenting, which are based on the concept of Islam that can be done to help parents overcome the problem of low self-esteem. The hypothesis of this study is Islamic effective parenting training to increase self-esteem of parents of children with mental retardation. This study using the experimental approach of pre and post test one group design. The research subject of five parents of children with mental retardation in SLB Pekanbaru Pelita Hati. Measuring instrument used is the self-esteem scale with 45 item. Analysis by calculating the mean difference in self-esteem in each subject before and after getting Islamic parenting training, Based on the results of data analysis showed Islamic parenting training has no significant effect in increasing self-esteemThis means Islamic Perenting less effective training enhances self-esteem of parents who have children with mental retardation.
\end{abstract}

Keywords: Islamic parenting, self-esteem, mental retardation

\section{Pendahuluan}

Keluarga merupakan pondasi utama dalam membentuk kepribadian anak. Sebagai lingkungan pertama tempat anak berinteraksi, mengembangkan pola kreativitas, maka orangtua mempunyai peranan yang penting dalam memberikan hidup, tanggung jawab dan berkewajiban mengusahakan perkembangan anak yang sehat, baik jasmani maupun rohani. Setiap orangtua juga mengharapkan hadirnya anak yang sempurna baik fisik maupun mental. Namun adakalanya harapan orangtua tidak sesuai dengan kenyataan sehingga anak yang dilahirkan tidak sempurna baik fisik maupun mental.
Salah satu ketidaksempurnaan anak yang dilahirkan adalah kondisi retardasi mental. Retardasi mental merupakan suatu keadaan penyimpangan tumbuh kembang seorang anak yang mencakup terhambatnya perkembangan fungsi kognitif dan sosial. Retardasi mental ditandai dengan keadaan perkembangan mental individu yang kurang sempurna atau tidak lengkap, dan hal ini dapat diketahui selama masa perkembangan sehingga berpengaruh pada kemampuan kognitif, bahasa, motorik, maupun kemampuan sosialnya (Wenar, 2006). Anak retardasi mental mengalami kesulitan dalam membina hidup sehari-hari, yang berkaitan dengan kemampuan mengurus diri, penyesuaian diri, 
kemampuan komunikasi dan sosialisasi serta yang berkaitan dengan permasalahan yang muncul dalam hubungannya dengan kelompok maupun individu disekitarnya (Depdiknas, 2003).

Penelitian menunjukkan bahwa orangtua sangat berperan penting dalam membantu anak retardasi mental. Sikap, pola asuh, kepercayaan diri orangtua yang memiliki anak retardasi mental juga berperan dalam membantu anak retardasi mental menghadapi hidupnya. Penelitian tentang penyesuaian diri orangtua yang memiliki anak retardasi mental ringan menemukan bahwa proses penyesuaian diri orangtua dari anak yang mengalami retardasi mental dipengaruhi oleh beberapa faktor seperti tingkat keparahan retardasi mental anak, status sosial ekonomi keluarga, jumlah anggota keluarga serta jenis kelamin anak (Zamralita \& Hastuti, 2003).

Penyesuaian diri orangtua saat memiliki anak dengan kondisi retardasi mental merupakan tantangan yang dihadapi oleh orangtua. Tak jarang orangtua merasa rendah diri, menghindar dari pergaulan sosial karena memiliki anak dengan kondisi yang tidak diharapkan seperti retardasi mental. Orangtua juga cenderung tidak bersemangat, menyesali diri bahkan pasrah dan putus asa memiliki anak dengan kondisi retardasi mental ini. Harga dirinya pun menjadi rendah dan cenderung menyalahkan diri sendiri. Padahal di dalam Islam, anak adalah amanah, bentuk kepercayaan Allah SWT kepada orangtua. Apapun kondisi anak dapat meningkatkan kualitas orangtua. Sebagaimana yang telah di firmankan Allah SWT dalam Al-Qur'an Surat At-Tahrim ayat 6 yang berbunyi :

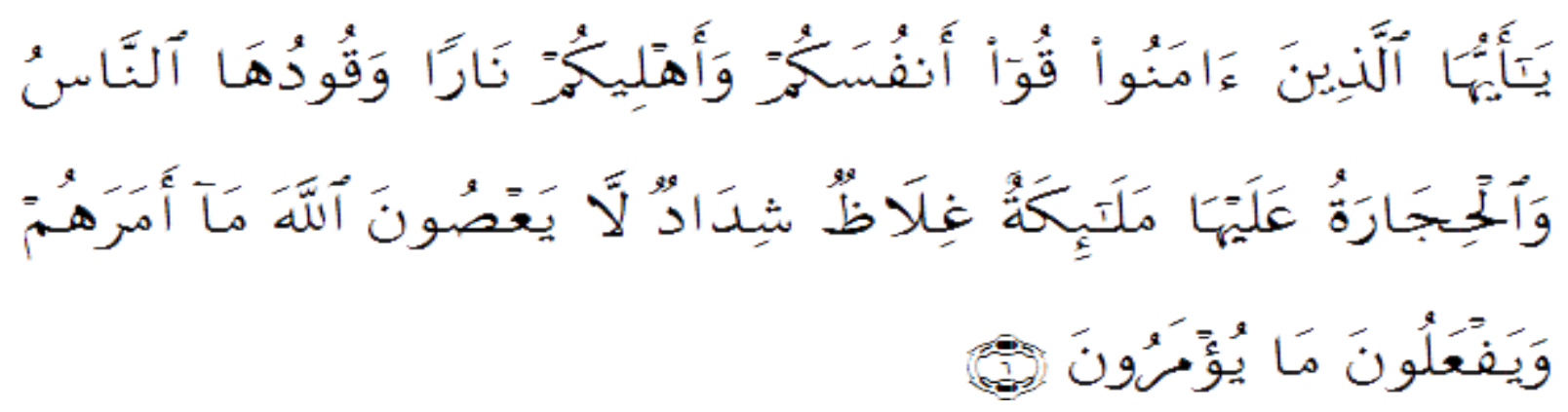

" Hai orang-orang yang beriman, peliharalah dirimu dan keluargamu dari api neraka yang bahan bakarnya adalah manusia dan batu; penjaganya malaikat-malaikat yang kasar, keras, dan tidak mendurhakai Allah terhadap apa yang diperintahkan-Nya kepada mereka dan selalu mengerjakan apa yang diperintahkan". Surat At-Tahrim ayat 6

Islamic parenting training merupakan suatu bentuk pelatihan tentang pengasuhan yang dilandaskan pada konsep Islam yang dapat dilakukan untuk membantu orangtua mengatasi masalah harga diri yang rendah. Harga diri yang baik akan mendukung orangtua memaksimalkan potensi anak retardasi mental yang dimilikinya. Kesadaran untuk mensyukuri dan menerima apapun kondisi anak yang dilahirkan sebagai amanah dan titipan Allah SWT perlu terus menerus dilatih disertai dengan pendekatan agama. Agama Islam mengajarkan pola asuh yang harus diterapkan orangtua termasuk kepada anak dengan kondisi retardasi mental. Pentingnya pengasuhan terhadap anak dijelaskan dalam Al-Qur'an Surat Lukman Ayat 13 yang berbunyi :

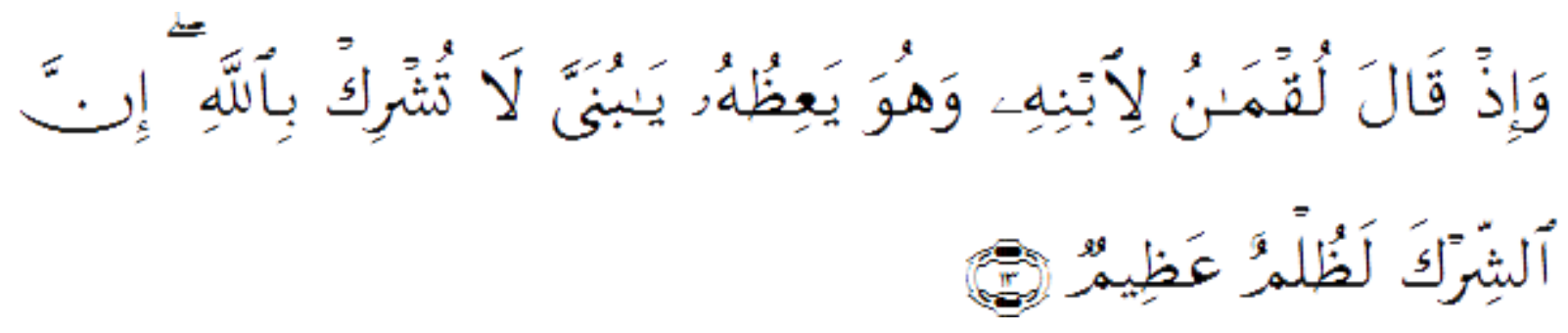

" dan (ingatlah) ketika Luqman berkata kepada anaknya, di waktu ia memberi pelajaran kepadanya: "Hai anakku, janganlah kamu mempersekutukan Allah, Sesungguhnya mempersekutukan (Allah) adalah benar-benar kezaliman yang besar". Surat Lukman Ayat 13

Melalui Training Islamic Parenting diharapkan orangtua dapat memiliki harga diri yang tinggi, menyadari potensi positif yang di- miliki anak retardasi mental meningkatkan kemampuan kognitif orangtua karena di dalam pelatihan mengandung unsur untuk mening- 
katkan pengetahuan orangtua tentang kondisi anak, meningkatkan kesadaran tentang bagaimana mensikapi anak dengan kondisi retardasi mental, tidak meyalahkan diri sendiri. Ajaran Islam juga mengatur bagaimana mengasuh dan mendidik anak. Pada awalnya tanggung jawab orang tua adalah sebagai pemberi, pelindung dan pendidik yaitu menjaga agar segala kebutuhannya terpenuhi dan menghindarkannya dari berbagai krisis. Ketika usia anak bertambah, anak memerlukan orang tua dengan cara yang lain, yaitu untuk membimbing, mengajar, menghibur dan menerangi, menjalin keakraban dan tempat berbagi rahasia. Pada setiap tahap, peran orang tua harus ditinjau kembali. Peran sebagai orang tua menuntut untuk terus menerus dan secara luwes menyesuaikan reaksi terhadap perkembangan kemampuan anak.

\section{Harga diri}

Menurut Minchiton (1993) harga diri bukanlah aspek tunggal saja, melainkan sebuah kombinasi dari beragam sifat dan perilaku yang terangkum pada aspek berikut ini:

1. Perasaan mengenai diri sendiri. Seseorang haruslah menerima dirinya secara penuh, apa adanya, mampu menilai diri kita sendiri tidak tergantung pada kondisi eksternal. Apapun yang terjadi kita dapat merasa nyaman dengan diri sendiri dan dapat menilai keunikan yang ada dalam diri kita tanpa menghiraukan karakter atau kemampuan yang tidak kita miliki ataupun yang kita miliki

2. Perasaan terhadap hidup. Perasaan terhadap hidup berarti menerima tanggung jawab atas sebagian hidup yang dijalaninya. Menerima dengan lapang dada atas segala masalah yang dihadapinya.

3. Hubungan dengan orang lain. Seseorang yang memiliki harga diri yang tinggi percaya bahwa dirinya patut dihargai dan dihormati dan mempunyai hak yang sama. Memandang setiap oranglain sama dan menghargai oranglain dalam setiap bentuk hubungannya.

\section{Islamic Parenting Training}

Islam mempunyai dasar dan tata cara tersendiri dalam mendidik anak. Karena dalam Islam, anak memiliki peran yang sangat penting. Training islamic parenting adalah bentuk pelatihan yang menggunakan kekuatan pola pengasuhan islami untuk dapat diterapkan kepada orangtua yang memiliki anak retardasi mental. Training Islamic parenting mengajarkan orangtua bagaimana agar mereka bersyukur atas kehadiran anaknya yang tidak sempurna secara mental. Training Islamic parenting akan mengajarkan orangtua dengan pola asuh yang berlandaskan pada Alquran dan Hadist. Karakteristik pola asuh islami adalah penekanan masalah religiusitas atau ideologi keagamaan dan motivasi-motivasi bagi orang tua yang mengasuh anakanaknya. Inilah yang membedakan antara Training Islamic parenting dengan pola asuh dari Barat secara umum.

Imam Al-Ghazali (dalam Abdurrahman, 2010) menyebutkan bahwa metode atau pola mendidik anak merupakan perkara yang terpenting dan paling utama. Pola mendidik anak dengan metode Rasulullah di antaranya: bercengkerama dengan anak, bersikap baik ketika memanggil anak, jangan mencelanya, bersikap lembut dan bijaksana, gali potensi anak, dukung anak untuk menekuni bidang keahlian yang sesuai bakatnya, mengajarkan akhlak mulia, mendoakan anak.

Berdasarkan teori di atas maka hipotesis dalam penelitian ini adalah Islamic parenting training efektif untuk meningkatkan harga diri orangtua yang memiliki anak retardasi mental.

\section{Metode}

\section{Desain dan prosedur}

Penelitian ini bertujuan untuk mengetahui efektivitas Islamic parenting training untuk meningkatkan harga diri orangtua yang memiliki anak retardasi mental. Peneliti melakukan pengukuran di awal sebelum pelatihan dilakukan (pre-test/pra pelatihan) dan pengukuran lainnya pada saat setelah pelatihan (post-test/paska pelatihan). Dengan demikian penelitian ini merupakan penelitian eksperimen. Desain eksperimen yang dilakukan merupakan eksperimental before-after study atau yang disebut juga dengan desain pretest/post-test atau disebut juga dengan A-BA design (Seniati dkk, 2009). Desain ini dapat mengukur suatu perubahan pada suatu situasi, fenomena, isu, masalah, atau sikap dan merupakan desain yang sesuai untuk menelaah efektivitas dari suatu program.

Kedua pengukuran tersebut (pre-test dan post-test) akan dibandingkan untuk melihat adanya pengaruh dari pelatihan yang dilakukan terhadap perubahan tingkat harga diri orangtua yang memiliki anak retardasi mental. Subjek penelitian diukur tingkat harga dirinya, setelah itu diberi pelatihan yang bertujuan untuk meningkatkan harga dirinya. Setelah pelatihan selesai, dilakukan pengukuran untuk mengetahui apakah harga diri subjek meningkat atau tidak melalui program Islamic parenting training ini.

\section{Subjek}

Subjek dalam penelitian ini adalah orangtua dari siswa Retardasi Mental di Sekolah Luar Biasa Pelita Hati Pekanbaru yang berjumlah 5 orang, dengan karakteristik :usia minimal 30 tahun, pendidikan minimal SMA 
dan bersedia mengikuti seluruh sesi pelatihan

\section{Alat Ukur}

Pengukuran variabel terikat dalam penelitian menggunakan skala harga diri orangtua yang disusun oleh peneliti berdasarkan aspek-aspek harga diri, yaitu : perasaan mengenai diri sendiri, perasaan terhadap hidup, hubungan dengan orang lain. aitem berjumlah 45 butir.

\section{Teknik Analisis Data}

Teknik analisis data kuantitatif yang digunakan dalam penelitian ini adalah analisis
Deskriptif dan non parametric.

Hasil

Dari tabel 1 menunjukkan skor harga diri subjek penelitian sebelum pelatihan berkisar dari skor 88 -111. Sedangkan reratanya adalah 98,8. Dari 1 skor mean harga diri subjek penelitihan setelah pelatihan berkisar 92 -104 . Sedangkan reratanya adalah 100.4. walaupun secara umum terjadi kenaikan namun ada satu subjek yang turun skor harga diri setelah dilakukan pelatihan.

\section{Tabel 1. Rerata Skor Sebelum Pelatihan (Pretest)}

\begin{tabular}{llll}
\hline No & Nama & Skor Pre Test & Skor post Test \\
\hline 1 & Y & 88 & 96 \\
2 & W & 91 & 92 \\
3 & M & 102 & 104 \\
4 & S & 111 & 108 \\
5 & K & 102 & 102 \\
\hline & Rerata & 98.8 & 100,4 \\
\hline
\end{tabular}

Tabel 2. Statistik Deskriptif Kelompok Eksperimen

\begin{tabular}{llllll}
\hline & N & Maksimal & Minimal & Mean & SD \\
\hline Pretest & 5 & 111 & 88 & 99.5 & 3.83 \\
Posttest & 5 & 108 & 92 & 100 & 2.67 \\
\hline
\end{tabular}

Dari tabel di atas nampak perubahan mean terjadi perubahan dari mean 99,5 sebelum pelatihan dan 100 setelah pelatihan. Hasil uni analisis dengan Wilcoxon $Z=-730$, Sig $=0.465(p>0.005)$. hal ini berarti tidak ada pengaruh signifikan Islamic parenting dalam meningkat harga diri orangtua yang memiliki anak retardarsi mental.

\section{Pembahasan}

Hasil penelitian menunjukkan bahwa Islamic perenting training tidak memiliki pengaruh signifikan untuk meningkatkan harga diri orang tua yang memiliki anak retardasi mental. Kurang efektifnya Islamic parenting training untuk meningkatkan harga diri orangtua yang memiliki anak retardasi mental disebabkan beberapa hal diantaranya sebagai berikut : konsep Islamic parenting kurang ta- jam, tidak ada screening bahwa orangtua telah menerapkan Islamic parenting, kemungkinan trainer menyampaikan materi tidak sesuai dengan modul, jarak waktu antara pemberian pre test dan post test terlalu dekat.

Efektivitas training Islamic parenting untuk meningkatkan harga diri orang tua ini membuat orangtua dapat memperbaiki perlakuan yang selama ini mereka berikan pada anak yang mengalami retardasi mental. Dalam kaitannya dengan pemeliharaan dan pengasuhan anak ini, ajaran Islam tertulis dalam Al-Qur'an, Hadits, maupun hasil ljtihad para ulama ( Intelektual Muslim ) telah menjelaskannya secara rinci, baik mengenai pola pengasuhan anak pra kelahiran maupun pasca kelahiran. Hal ini sebagaimana ditegaskan dalam Al-Qur'an surat Al-Kahfi ayat 46 yang berbunyi :

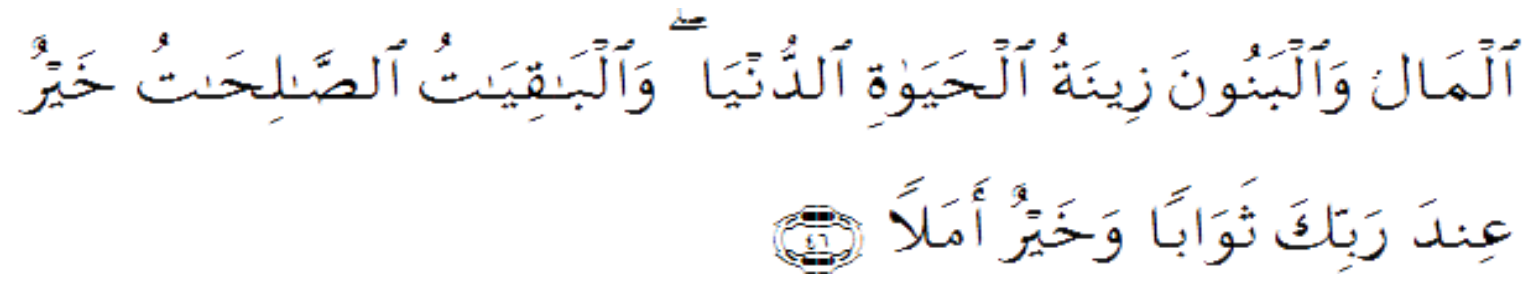


"harta dan anak-anak adalah perhiasan kehidupan dunia tetapi amalan-amalan yang kekal lagi saleh adalah lebih baik pahalanya di sisi Tuhanmu serta lebih baik untuk menjadi harapan ." Surat Al-Kahfi ayat 46

Namun berdasarkan evaluasi yang dilakukan maka efektifitas dapat dilihat dari kriteria seperti yang diungkapkan oleh Kirkpatrick ( Rigio dan Sorenson, 2003 ).

\section{a. Kriteria reaksi}

Kriteria reaksi merupakan ukuran reaksi dari subjek. Termasuk di dalamnya asesmen nilai program, banyaknya materi yang diterima, dan partisipasi subjek. Kriteria reaksi biasanya dinilai melalui evaluasi yang diberikan setelah mengikuti program. Kriteria reaksi tidak mengukur apakah pelajaran telah berlangsung, tetapi menilai pendapat subjek mengenai pelatihan dan materi yang diberikan. Berdasarkan lembar evaluasi rata-rata para peserta merasa sangat puas dengan materi yang disampaikan pada saat pelatihan sebagai bekal bagi mereka untuk lebih memahami tentang seksualitas itu sendiri. Hal ini tercermin dari harapan peserta bahwa sebaiknya pelatihan ini diberikan setiap tiga bulan sekali untuk meningkatkan pemahaman mereka. Materi yang disampaikan pelatih dalam sesi pelatihan dinilai oleh peserta yakni orangtua dari anak remaja retardasi mental ringan sebagai sesuatu yang sangat penting dan berguna bagi mereka seperti yang termuat dalam lembar evaluasi serta kutipan hasil wawancara dengan salah satu orangtua subjek berikut ini.

"Saya sangat senang sekali ada pelatihan Selama ini saya cukup bingung dalam mengahadapi anak saya, kadangkala tak sabar dan kesal juga...habis gimana ya agak susah juga menjelaskan karena mereka kan agak lambat, jadi agak beda juga cara menyampaikan sesuatu dibanding kalau sama anak kita yang normal"

Informasi yang memiliki tingkat relevansi tinggi dengan kehidupan sehari-hari akan cenderung mudah diingat dan dipahami oleh seseorang dibandingkan dengan informasi yang jauh dari kenyataan (Rakhmat, 2004 ). Bahasan tentang materi anak retardasi mental dan bagaimana mengasuhnya berdasarkan konsep Islami yang sangat dibutuhkan oleh orangtua untuk menangani berbagai macam masalah terkait dengan hambatan yang dimiliki oleh anak-anak mereka. Adanya modul panduan dinilai sangat membantu peserta dalam menjelaskan tentang kelebihan dan kekurangan anak mereka maupun diri mereka sendiri sebagai orangtua.

\section{b. Kriteria belajar}

Kriteria belajar merupakan ukuran banyaknya materi yang telah diberikan. Biasanya kriteria belajar berbentuk tes singkat untuk menilai banyaknya materi yang dipahami subjek. Saat sesi pelatihan dilakukan untuk orangtua maka peserta dibagi dalam kelompok kecil untuk kemudian diberi tugas sesuai dengan materi yang diberikan dan metode yang diterapkan. Agar pelatihan dapat berjalan efektif dan metode dapat diterapkan dengan maksimal maka peserta di bagi dalam kelompok kecil.

\section{Kesimpulan}

Berdasarkan hasil analisis data dan pembahasan penelitian, maka dapat disimpulkan bahwa training Islamic parenting kurang efektif dalam meningkatkan harga diri orang tua. Hal ini terlihat dari terjadinya perubahan yang kurang signifikan antara skor rerata harga diri orangtua pada pretest dan posttest.

\section{Daftar Pustaka}

Abdurrahman, Jamal. (2010). Islamic Parenting (Pendidikan Anak Metode Nabi). Solo : PT Aqwam Media Profetika

Altalib,Hisham, Yahya, (1991). Traning Guide for Islamic Workers. Hemdon. The International Institute of Islamic Thougt Al-Qur'an digital

American Psychiatric Association. (2000). Diagnostic and Statistical Manual of Mental Disorders (4th ed.). Washington, DC: American Psychiatric Association.

An-Nahlawi, A. (1996). Pendidikan Islam di Rumah, Sekolah dan Masyarakat (Terjemahan). Jakarta : Gema Insani Press

Arikunto, Suharsimi. (2006). Prosedur Penelitian, Suatu Pendekatan Praktik. Jakarta. Rineka Cipta

Azwar, S. (2002). Validitas dan Reliabilitas, Cetakan ketiga, Yogyakarta: Pustaka Pelajar

Botsari, E. M. (2001). Personality Characteristics of Greek Mothers of Children with Special Needs who are Involved in Special Needs Support Center. Journal of educational studies.

Branden,(1992). The Power of Self Esteem. Florida: Health Communication. Inc

Hastuti dan Zamralita (2004). Penyesuaian Diri Orang Tua Yang Memiliki Anak Retardasi Mental Ringan. Arkhe jurnal ilmiah Psikologi, Volume 9 No2, 90-98. 
Hurlock, E.B. (1999). Psikologi Perkembangan Sepanjang Rentang Kehidupan. Jakarta: Airlangga

Huroniyah, F. 2004. Hubungan antara Persepsi Pola Asuh Islami terhadap Kematangan Beragama dan Kontrol Diri. Tesis. Yogyakarta: Pascasarjana Universitas Gadjah Mada

Kamus Besar Bahasa Indonesia. (2005). Jakarta. Balai Pustaka

Latipun. 2002. Psikologi Eksperimen. Malang. UMM.Press

Maulina, B dan Sutatminingsih, Raras R. 2005. Stres ditinjau dari Harga Diri pada Ibu yang Memiliki Anak Penyandang Retardasi Mental. Jurnal Psikologia. Vol. 1 No.1 Juni 2005

Mangunsong, F. dkk. (1998). Psikologi dan Pendidikan Anak Luar Biasa. Cetakan 1. Jakarta : LPSP3 UI

Minchinton,J. (1993). Maximum Self Esteem. The Handbook For Reclaiming Your Sense of Self Worth. Kualalumpur. Golden Books Centre.Sdn.Bhd

Nevid, J.S., Rathus, S.A. \& Greene, B. (2005). Psikologi Abnormal, Edisi kelima, Jilid 2. Jakarta: Penerbit Erlangga.

Nurmitasari, I. (2011). Pengasuhan Islami Single Parent terhadap Kesehatan
Mental Anak Remaja. Studi Kasus Keluarga Ibu Nunung di Seturan Yogyakarta. Skripsi. UIN Suka Yogyakarta.

Riggio, R.E., Ciulla, J., \& Sorenson, G. (2003). Leadership education at the undergraduate level: A liberal arts approach to leadership development. In S.E. Murphy \& R.E.

Sattler, J.E. (2002). Assessment of Children Behavioral and Clinicial Applications. Third edition. San Diego: Jerome M. Sattler, Publisher.

Seniati dkk. (2009) Psikologi Eksperimen. PT Indeks. Jakarta

Siegel,S. (1997). Statistik Non Parametrik untuk Ilmu-imu Sosial. Jakarta. PT Gramedia

Sugiyono. (2009). Metode Penelitian Kualitatif Kuantitatif dan R\&D. Bandung. Alfabeta

Sukur, ddk. (2012). Gambaran Konsep Diri Orangtua yang Memiliki Anak retardasi Mental di SLB C YPPLB Cenderawasih Makasar. Jurnal Vol. 1 No. 5 ISSN 2302-1721

Wenar. C. \& Kerig, P. (2006). Developmental Psychopatology. From Infancy to Adolescence. Fifth edition. New York: Mc. Graw Hill Inc. 